\title{
Multidisciplinary inpatient rehabilitation improves the long-term functional status of geriatric hip-fracture patients
}

\author{
Daniel Pfeufer ${ }^{1^{*}+}$ (D), Christian Kammerlander ${ }^{1+}$, Christian Stadler ${ }^{1,2}$, Tobias Roth $^{3}$, Michael Blauth ${ }^{4,5}$, \\ Carl Neuerburg ${ }^{1}$, Wolfgang Böcker ${ }^{1}$, Christian Zeckey ${ }^{1}$, Monika Lechleitner ${ }^{6}$ and Markus Gosch ${ }^{7}$
}

\begin{abstract}
Background: As the world population ages, the number of hip-related fractures in the elderly is steadily increasing. These fractures generate a major worldwide healthcare problem and frequently lead to deterioration of life quality, mobility and independence in activity of daily life of geriatric patients. At present, many studies have investigated and proved benefits of multidisciplinary orthogeriatric care for elderly hip-fracture patients. Only few studies however, have analyzed treatment concepts for those patients directly following discharge from hospital in specialized rehabilitation centers. The aim of this study was to evaluate effects of a multidisciplinary inpatient rehabilitation on the shortand long-term functional status of geriatric patients who suffered from hip fracture.

Methods: A total of 161 hip-fracture patients aged 80 years and above, or additionally 70 years and above suffering from age-typical multimorbidity were included in this study. Patients who had an initial Barthel Index lower than 30 points were excluded from this study, as most of these patients were not able to attend a therapy at the rehabilitation center due to a poor functional status. The patients were separated into two subgroups dependent on the availability of treatment spots at the rehabilitation center. No other item was used to discriminate between the groups. Group A $(n=95)$ stayed an average of 21 days at an inpatient rehabilitation center that specialized in geriatric patients. Group B $(n=66)$ underwent the standard postoperative treatment and were sent home with further treatment by their general practitioner, nursing staff and physiotherapists. To evaluate the patients'functional status over the course of time we used the Barthel Index, which was evaluated for every patient on the day of discharge, as well as during checkups after 3, 6 and 12 months.
\end{abstract}

Results: The average Barthel Index at the day of discharge was $57.79 \pm 14.92$ points for Group A and $56.82 \pm 18.76$ points for Group B $(p=0.431)$. After 3 months, the average Barthel Index was 82.43 points for Group A and 73.11 points for group $B(p=0.005)$. In the 6-month checkup Group A's average Barthel Index was 83.95 points and Group B's was 74.02 points ( $p=0.002$ ). After 12 months, patients from Group A had an average Barthel Index of 81.21 while patients from Group B had an average Barthel Index of 69.85 ( $p=0.005)$.

Conclusion: The results of this study reveal a significantly better outcome concerning both, short-term and longterm functional status after 3, 6 and 12 months for geriatric hip-fracture patients, who underwent an inpatient treatment in a rehabilitation center following the initial therapy.

\footnotetext{
*Correspondence: Daniel.Pfeufer@med.uni-muenchen.de

${ }^{\dagger}$ Daniel Pfeufer and Christian Kammerlander are shared first authors

1 Department of General, Trauma and Reconstructive Surgery, University

Hospital Ludwig-Maximilians-University (LMU) Munich, Munich, Germany

Full list of author information is available at the end of the article
}

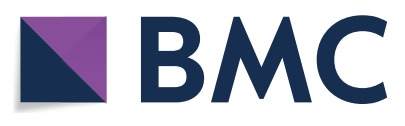

(c) The Author(s) 2020. This article is licensed under a Creative Commons Attribution 4.0 International License, which permits use, sharing, adaptation, distribution and reproduction in any medium or format, as long as you give appropriate credit to the original author(s) and the source, provide a link to the Creative Commons licence, and indicate if changes were made. The images or other third party material in this article are included in the article's Creative Commons licence, unless indicated otherwise in a credit line to the material. If material is not included in the article's Creative Commons licence and your intended use is not permitted by statutory regulation or exceeds the permitted use, you will need to obtain permission directly from the copyright holder. To view a copy of this licence, visit http://creativeco mmons.org/licenses/by/4.0/. The Creative Commons Public Domain Dedication waiver (http://creativecommons.org/publicdomain/ zero/1.0/) applies to the data made available in this article, unless otherwise stated in a credit line to the data. 
Keywords: Orthogeriatric care, Hip fracture, Geriatric patients

\section{Background}

As the world population ages, the number of hip-related fractures in the elderly is steadily increasing, making these fractures a major health care problem all around the world $[1,2]$. With growing numbers of fragility fractures, health care provider will face not only demanding medical challenges regarding the treatment of these mostly frail and multimorbid patients, but also a major financial burden [3-6].

Hip-related fractures frequently lead to deterioration regarding geriatric patients' mobility, life quality and eventually independence in everyday life. Less than half of hip-fracture patients aged 65 years and above regain their prefractural mobility within the first postoperative year $[7,8]$. Furthermore, higher rates of morbidity and mortality are well known and proven consequences of fragility fractures in the elderly $[9,10]$.

At present, many studies have investigated and proved the benefits of multidisciplinary orthogeriatric care for elderly hip-fracture patients [11-13]. Only few studies however, have analyzed treatment concepts for those patients directly following the discharge from hospital in specialized rehabilitation centers [14].

Supplemental to multidisciplinary orthogeriatric care, rehabilitation programs specialized in geriatric patients may further improve the clinical outcome regarding the treatment of fragility fractures, in particular by improving the patients' functional status and independence in activities of everyday life [15]. The World Health Organization defines the maximization of function and the minimization of limitation in activity and restriction of participation caused from an impairment or disease, as the primary objectives of rehabilitation [16]. Although there are many well implemented rehabilitation concepts for patients with special diseases or impairments such as cardiovascular, pulmonary or neurological disorders, yet there are few established rehabilitation programs specialized in the highly demanding needs of orthogeriatric patients [17-20].

The aim of our study was to evaluate the effects of a multidisciplinary inpatient rehabilitation, not only on the short-term, but also on the long-term functional status of orthogeriatric patients who suffered from hip-related fracture.

\section{Methods}

\section{Study design and population}

This study is a retrospective cohort study (Level of evidence III). The study was conducted at the University
Hospital of Innsbruck, which is running a Geriatric Fracture Center specialized in elderly patients suffering from typical age-related problems like cardiovascular diseases or osteoporosis. An orthogeriatric co-management model with trauma surgeons and geriatricians taking care of the patients at the same ward, is implemented at this Geriatric Fracture Center in order to adequately address not only the patient's fractures, but also age-typical comorbidities [21]. The initial treatment for all patients took place at this level-I trauma center. The rehabilitation center, which is dedicated to the treatment of geriatric patients, is located at the state hospital of Hochzirl. A team consisting of geriatricians, nurses, physiotherapists, speech therapists, psychologists and social workers provide multidisciplinary care to the rehabilitation center's geriatric patients, with specialized treatments and exercises on a regular basis in order to restore the patient's prefractural ability to perform activities of daily living as well as possible. Trauma surgeons are not present at the rehabilitation center permanently, but can be reached out to at all times if there is any need for a surgical consultation. The patients who were not admitted to the specialized clinic were sent home with further treatment by their general practitioner, nursing staff and physiotherapists. All data included in this study were collected during the patients' clinical treatment and was analyzed retrospectively. As such, there was no study-related change to the standard medical treatment protocol.

Patients older than 80 years with hip fracture treated between August 2009 and November 2011 were included in this study. Furthermore, patients aged 70 to 79 years with hip fracture were included if they additionally suffered from age-typical multimorbidity according to the definition of the German Society of Geriatrics and Gerontology [22]. Further inclusion criteria were a Barthel Index of at least 30 points on the day of discharge from the surgical ward and a complete follow-up over 3, 6 and 12 months.

The study population was retrospectively separated into two subgroups dependent on the availability of free treatment spots at the geriatric rehabilitation center: Group A $(n=95)$ stayed a mean of $21 \pm 8$ days at the rehabilitation center following the surgical treatment (from those 95 patients, 90 patients $(=95 \%)$ were directly discharged to the rehabilitation center, three patients $(=3 \%)$ started the rehab within 7 days after the surgical therapy's end, two patients $(=2 \%)$ attended rehab within 19 days). Patients from Group B $(n=66)$ received the standard guidelineconform surgical treatment and were discharged home or 
to a nursing home. There was no difference regarding the acute phase care (time from admission to hospital to surgery) or regarding the postoperative restrictions (weight bearing) between the two study groups. The mean length of stay at the hospital was $11.61 \pm 5.95$ days.

All patients were advised to attend checkups after 3, 6 and 12 months at the outpatient clinic.

From a total number of 475 patients with hip-related fractures, 161 patients-134 women (83\%) and 27 men (17\%) -with a mean age of $82.77 \pm 6.51$ years met the inclusion criteria mentioned above.

Initially we excluded patients with a Barthel Index lower than 30 points $(n=125)$. From the remaining study population $(n=350), 195$ patients attended the inpatient rehabilitation at the geriatric rehabilitation center following the surgical treatment (Group A) and 155 patients were discharged home or to a nursing home following the surgical treatment (Group B). In Group A, a total of 21 patients $(=10.77 \%)$ died within the follow-up-period of 12 months and 79 patients $(=40.51 \%)$ from Group A did not complete the entire follow-up. Altogether we registered a drop-out of 100 patients $(=51.28 \%)$ resulting in a population of 95 patients for Group A.

In Group B, a total of 16 patients $(=10.32 \%)$ died within the follow-up-period and 73 patients $(=47.10 \%)$ from Group B did not complete entire follow-up-plan consisting of checkups after 3, 6 and 12 months. We registered a drop-out of 89 patients $(=57.42 \%)$ and 66 remaining patients for Group B.

Accordingly, we registered an overall drop-out rate of $54.00 \%(n=189)$ from those 350 patients who met all of our inclusion criteria resulting in a study population with a total number of 161 patients. For detailed numbers regarding the drop-out please see Fig. 1.

There is a high overall drop-out rate of $54.00 \%$ but no significant difference between Group $\mathrm{A}=51.28 \%$ and Group B $=57.42 \%$.

Patients suffering from one of the following hip-related fractures were included: acetabular fracture, femoral neck fracture, femoral shaft fracture, pubic bone fracture, periprosthetic fracture of the femoral bone and

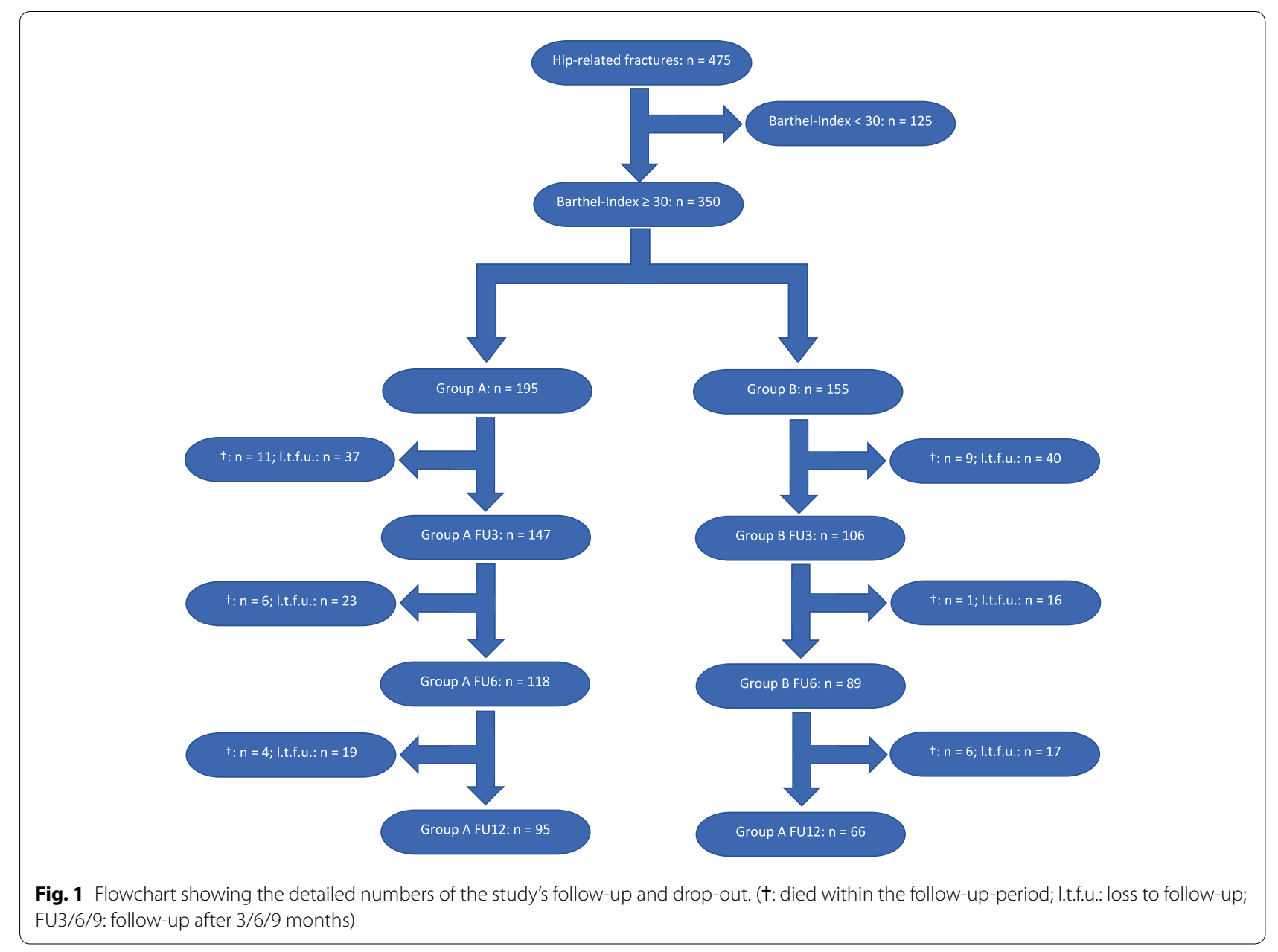


trochanteric fracture (Table 1). The mean follow-up was $372 \pm 26$ days.

\section{Data collection}

At the time of admission to hospital each patient was surveyed regarding basic information like age, gender, diagnosis, initial treatment, and comorbidities.

On day of discharge we surveyed each patient regarding the current functional status using the Barthel Index, which is used to quantify the patient's ability to act in activities of daily life, by measuring the occurrence of urinary or fecal incontinence, the ability to perform hair grooming, dressing, feeding, walking, transferring (for example from chair to bed), climbing stairs, using the toilet and bathing independently. Each question is answered by choosing one out of two to four given answers, which are rated in steps of five points with zero points being the minimum for every answer and 10 to 20 points being the maximum depending on the number of given answers [23]. Resulting in an overall score of 100 points at most (=best achievable score) to 0 points at least (=worst achievable score), the Barthel Index is a reliable parameter to measure the independence of patients in daily living [23-25]. During checkups after 3, 6 and 12 months every patient's basic data and Barthel Index were measured again.

The data collection was carried out by study nurses. The follow-up ended in November 2012.

\section{Statistics}

SPSS version 25.0 (2017) was used for the statistical analysis. To test for normal distribution KolmogorovSmirnov test was performed. To analyze non-normally distributed parameters as well as to calculate the significance of the differences between the average scores of the two study groups, non-parametric Mann-Whitney $\mathrm{U}$ test was used. $T$-test was performed to analyze differences regarding normally distributed parameters within the two study groups and Chi-square test was used to evaluate nominally scaled data.

As for metric scaled data, arithmetic mean value and the standard deviation were calculated and these two parameters as arithmetic mean value \pm standard deviation reported.
To evaluate the effect of an inpatient rehabilitation and certain patient characteristics such as age and gender on the outcome after 12 months, multiple linear regression analysis was conducted. The significance level was defined by $p=0.05$.

\section{Results}

We included 161 geriatric patients with hip-related-fractures in this study. The mean age was $82.77 \pm 6.51$ years. $83 \%(n=134)$ of the study participants were female while $17 \%(n=27)$ were male. The distribution of the baseline patient data within the two study groups is shown in Table 1. The most common types of fractures in the study population were femoral neck fractures (44\%; $n=71)$, trochanteric fractures $(36 \% ; n=58)$ or pubic bone fractures $(12 \% ; n=20)$. Other included types of fractures were acetabular fractures, femoral shaft fractures and periprosthetic fractures. The detailed numbers are listed in Table 2. Overall time from admission to hospital to surgery was $22.79 \pm 18.25 \mathrm{~h}$. There was no significant difference regarding time to surgery between Group A (22.74 $\pm 16.68 \mathrm{~h})$ and Group B $(22.86 \pm 20.91 \mathrm{~h})$ $(p=0.974)$.

The average Barthel Index on day of discharge was $57.39 \pm 16.56$ points within the entire study population. After the initial treatment, the study participants either attended a treatment at the rehabilitation center or underwent the standard aftercare-thereby representing our retrospectively created study Groups "A" and "B".

The mean length of stay at the hospital was $11.61 \pm 5.95$ days. Patients from Group A stayed an

Table 2 Types of fractures and their frequency within the study population

\begin{tabular}{lccr}
\hline & Rehabilitation & $\begin{array}{l}\text { Standard } \\
\text { treatment }\end{array}$ & Total \\
\hline Acetabular fracture & 4 & 1 & 5 \\
Femoral neck fracture & 43 & 28 & 71 \\
Femoral shaft fracture & 2 & 2 & 4 \\
Pubic bone fracture & 5 & 15 & 20 \\
Periprosthetic fracture & 3 & 0 & 3 \\
Trochanteric fracture & 38 & 20 & 58 \\
Total & 95 & 66 & 161 \\
\hline
\end{tabular}

Table 1 Baseline patient data within the study population

\begin{tabular}{lcccc}
\hline & Rehabilitation $(\boldsymbol{n = 9 5 )}$ & Standard treatment $(\boldsymbol{n = 6 6 )}$ & Overall $(\boldsymbol{n = 1 6 1 )}$ & $\boldsymbol{p}$ value \\
\hline Age (years) & $82.76( \pm 6.16)$ & $82.79( \pm 7.04)$ & $82.77( \pm 6.51)$ & 0.978 \\
Female patients & $81(85 \%)$ & $53(80 \%)$ & $134(83 \%)$ & 0.407 \\
Follow-up (days) & $372.77( \pm 24)$ & $371( \pm 29)$ & $372( \pm 26)$ & 0.626 \\
\hline
\end{tabular}


average of $12.05 \pm 5.24$ days at the hospital while patients from Group B stayed averagely $10.97 \pm 6.84$ days $(p=0.032)$.

For these two groups, we found the following outcomes: we retrospectively analyzed the Barthel Index on day of discharge for each subgroup separately. Group A had an initial average Barthel Index of $57.79 \pm 14.92$ points while Group B's average Barthel Index on day of discharge was $56.82 \pm 18.76$ points $(p=0.431)$. The patients were either discharged to the geriatric rehabilitation center (Group A), respectively, home or to a nursing home (Group B). From then on, the Barthel Indices were collected separately for each group during the checkups after 3, 6 and 12 months.

After 3 months, the average Barthel Index of Group A was $82.43 \pm 17.95$ points and Group B's was $73.11 \pm 21.03$ points $(p=0,005)$. In the 6 -month checkup, there was a mean of $83.95 \pm 18.65$ Barthel Index points in Group A while Group B's mean Barthel Index was $74.02 \pm 20.72$ points $(p=0.002)$. At the last checkup, 12 months after the initial treatment Group A's average Barthel Index was $81.21 \pm 20.79$ points, and Group B's was $69.85 \pm 25.42$ points $(p=0.005)$ (Fig. 2).

The average difference between the initial Barthel Index and the index reported after 3 months was $+24.64 \pm 16.77$ points for Group A and $+16.29 \pm 18.92$ points for Group B $(p=0,008)$. After 6 months, the difference raised to $+26.16 \pm 18.77$ points in Group A and $+17.19 \pm 18.06$ points in Group B $(p=0.004)$. The improvement regarding the Barthel Index from the day of discharge to the 12-month follow-up was $23.42 \pm 20.12$ points for Group A and $13.03 \pm 20.67$ points for Group B $(p=0.003)$ (Fig. 3).

The results of the Mann-Whitney U test are shown in Table 3.

The multiple linear regression analysis evaluates the effects of an inpatient rehabilitation, the patients age,

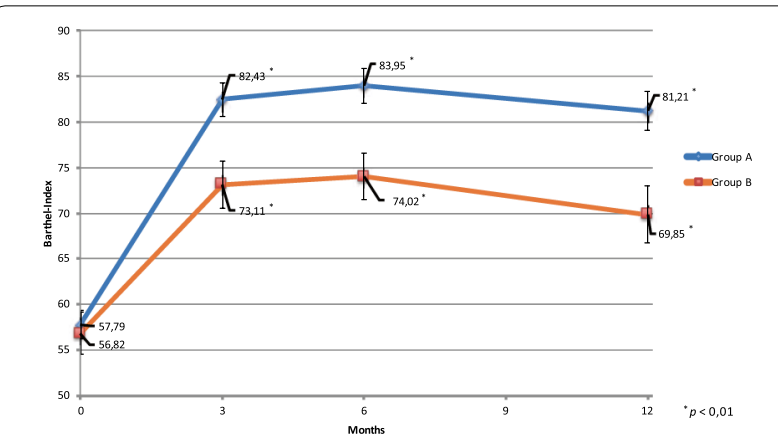

Fig. 2 Differences regarding the development of the average Barthel Indices during the follow-up period. Barthel Indices were collected at day of discharge, and after 3, 6 and 12 months

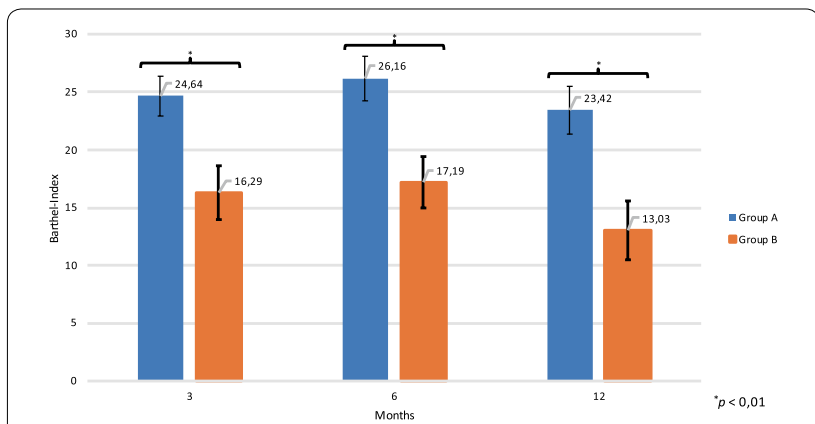

Fig. 3 Average difference between the Barthel Indices on day of discharge and the Barthel Indices collected during the follow-up period after 3,6 and 12 months

gender and Barthel Index collected at day of discharge on the Barthel Index measured after 12 months. It showed that participation in an inpatient rehabilitation, on average improved the Barthel Index after 12 months by 11.25 points $(p<0.001)$, while females showed an average decline in the Barthel Index by 9.88 points $(p=0.016)$ and every additional year in the patients age by 0.58 points $(p=0.019)$. Additionally, a higher Barthel Index at day of discharge resulted in an averagely improved Barthel Index 12 months later. Detailed results of the multiple linear regression analysis are shown in Table 4.

\section{Discussion}

The aim of this study was to evaluate not only the short, but also the long-term impact of a multidisciplinary inpatient rehabilitation on the functional status of orthogeriatric patients.

Previous studies have investigated and mostly proved the benefits of an inpatient rehabilitation for geriatric hip-fracture patients [14]. However, there are relatively few studies regarding the long-term functional outcome over 12 months-especially when it comes to the use of a reliable parameter for measuring the functional status like the Barthel Index [14].

Our study revealed a significantly better outcome for orthogeriatric patients suffering from hip-related fractures, regarding the functional status over 3 and 6 , and even over 12 months, compared to patients who received the standard postsurgical aftercare.

We included 161 patients with hip-related fractures aged older than 80 years, or additionally patients older than 70 years suffering from age-typical multimorbidity-in this study. The two study groups were created retrospectively with the main criteria being the patient's place of discharge, which depended on the availability of free treatment spots at the rehabilitation center. With a mean age of 82.77 years and the distribution of fractures 
Table 3 Results of the Mann-Whitney $U$ test for the non-normally distributed parameters

\begin{tabular}{lcccc}
\hline & Rehabilitation & Standard treatment & Overall & p value \\
\hline Barthel Ind. on day of discharge & $57.79 \pm 14.92$ & $56.82 \pm 18.76$ & $57.39 \pm 16.56$ & 0.431 \\
Barthel Ind. after 3 months & $82.43 \pm 17.95$ & $73.11 \pm 21.03$ & $78.61 \pm 19.75$ & 0.005 \\
Barthel Ind. after 6 months & $83.95 \pm 18.65$ & $74.02 \pm 20.72$ & $79.88 \pm 20.07$ & 0.002 \\
Barthel Ind. after 12 months & $81.21 \pm 20.79$ & $69.85 \pm 25.42$ & $76.55 \pm 23.41$ & 0.005 \\
Difference in Barthel Ind. after 3 months & $+24.64 \pm 16.77$ & $+16.29 \pm 18.92$ & $+21.22 \pm 18.10$ & 0.008 \\
Difference in Barthel Ind. after 6 months & $+26,16 \pm 18,77$ & $+17,19 \pm 18,06$ & $+22,48 \pm 18,95$ & 0.004 \\
Difference in Barthel Ind. after 12 months & $+23.42 \pm 20.12$ & $+13.03 \pm 20.67$ & $+19.16 \pm 20.93$ & 0.003 \\
\hline
\end{tabular}

Table 4 Results of the multiple linear regression analysis regarding the effects of an inpatient rehabilitation and certain patient characteristics such as age, gender and Barthel Index at day of discharge on the Barthel Index measured after 12 months

\begin{tabular}{lccrrr}
\hline & Regr. coefficient & Standard error & Beta & $\boldsymbol{T}$ & $\boldsymbol{p}$ value \\
\hline Rehabilitation & 11.246 & 3.071 & 0.237 & 3.662 & 0.000 \\
Age & -0.584 & 0.246 & -0.162 & -2.377 & 0.019 \\
Gender (female) & -9.881 & 4.069 & -0.158 & -2.428 & 0.016 \\
Barthel Ind. at discharge & 0.606 & 0.096 & 0.428 & 6.298 & 0.000 \\
\hline
\end{tabular}

shown in Table 2, our study population fairly represents the typical frailty-related hip-fracture population [26].

Commonly resulting in a deterioration regarding mobility, life quality and independence in activities of everyday life, fragility fractures are a major threat to orthogeriatric patients [7, 8]. Furthermore, poor functional status is independently associated with higher mortality among geriatric patients [25, 27]. With this study, we intended to evaluate an easily viable approach for enhancing orthogeriatric patients' functional status by sending them to a specialized rehabilitation center, as the patients' functional status is-along with the patients' mobility-one central outcome parameter when it comes to maintaining patients' quality of life, as well as to reduce the mortality rate of geriatric hip-fracture patients. To measure and evaluate the study participants' functional outcome, we chose the Barthel Index as it has been proven as a reliable parameter for describing patients' functional status [23-25].

Early mobilization of geriatric hip-fracture patients is a very important element of the postsurgical aftercare. It is known to reduce the incidence of hospital-related health issues such as delirium or hospital-acquired pneumonia, as well as it is known to lower the in-hospital mortality [28, 29]. Also, early interventions after hip-fracture surgery, such as physiotherapy, are likely to improve the patients' short-term functional outcomeespecially the mobility $[30,31]$. A major problem of immobilization is atrophy of muscles. Even short-term muscle disuse of less than 10 days can lead to severe muscle atrophy and in further consequence to the development of sarcopenia [32]. In order to avoid these serious consequences of immobilization, early interventions encouraging the regain of the patients' prefractural functional status may be a feasible approach for a better long-term outcome, regarding the ability to act independently in activities of daily life among orthogeriatric patients.

Our study's findings-although several limitations may impair the findings' reliability - revealed not only a shortterm benefit over 3 and 6 months, but also a long-term benefit over 12 months, regarding the functional status of geriatric hip-fracture patients who stayed a mean of 21 days at a rehabilitation center specialized in this challenging patient population, in comparison to patients who received the standard postsurgical aftercare without rehabilitation. In addition, the mean Barthel Index Score of Group A still improved from the 3-month checkup to the 6-month checkup, while the average Barthel Index Score from Group B barely improved (Fig. 2). Due to the complexity and the diversity of every patient's process of recovery, we are not able to determine the exact reasons for the better outcome of Group A regarding the functional status. It might be possible that early mobilizing interventions directly followed by a multimodal exercise program at the rehabilitation center have given patients from Group A the opportunity to gain and maintain enough muscle strength and coordinative skills, enabling 
them to perform more independently in activities of daily life than patients from Group B.

\section{Limitations}

There are several limitations to this study. The study's design is a retrospective uncontrolled single-center setting. The study population consists exclusively of geriatric hip-fracture patients treated at a trauma center specialized on orthogeriatrics. Therefore, our findings relate to this special group of patients and may not be generalizable to other populations of patients or health care settings. Furthermore, we excluded patients with a Barthel Index lower than 30 points from this study. So, we cannot draw conclusions regarding an inpatient rehabilitation's effects on patients with very low functional status. Also, female patients are over-represented in this study resulting in an under-representation of the male proportion. Therefore, the significance of this study's findings regarding male patients is limited.

The place of discharge (rehabilitation center, home, nursing home) depended solely on the availability of free treatment spots at the rehabilitation center. Still-due to the retrospective character of this study-we cannot determine for sure if there were certain characteristics to patients, making it more likely getting discharged to the rehabilitation center than characteristics of other patients.

The high drop-out rate of $54 \%$ of the initial study population represents another limitation and needs to be considered when interpreting the findings of this study.

Additionally, the use of a single endpoint (Barthel Index) is a big limitation to this study. More measures, for example including gait speed, grip strength or cognitive function would have been additional important parameters when it comes to evaluating the effects of an inpatient geriatric rehabilitation.

\section{Conclusion}

The results of this study reveal a significantly better outcome regarding the long-term functional status of geriatric hip-fracture patients who stay an average of 21 days at a geriatric rehabilitation center, directly following the discharge from hospital. In particular, the study's findings suggest not only a short-term-benefit from the geriatricrehabilitation within 3 months after the initial therapy, but also a long-term beneficial outcome after 6 and even 12 months.

From our scope of view, an inpatient rehabilitation as part of the postsurgical aftercare might be a feasible approach to restore the patients prefractural mobility and independence in activities of daily life.

Acknowledgements

Not applicable.

\section{Authors' contributions}

DP analyzed and interpreted the data of this study and was a major contributor in writing the manuscript. CK was a main contributor in designing and conducting this study as well as in collecting the data analyzed in this study. CS analyzed and interpreted the data and was a main contributor in writing the manuscript. TR and ML were main contributors in collecting the data analyzed in this study. MB contributed in designing this study. CN, WB and CZ contributed in writing this manuscript and substantively revised it. MG was a main contributor in designing, conducting and supervising this study. All authors read and approved the final manuscript.

\section{Funding}

No funding was retrieved for conducting this study.

\section{Availability of data and materials}

The datasets used and analyzed during the current study are not available publicly as data were pseudonymized but are available from the corresponding author on reasonable request.

\section{Ethical approval and consent to participate}

According to the Ethics Committee of the Medical University of Innsbruck no ethics approval is required for retrospective observational studies.

\section{Consent of publication}

Not applicable.

\section{Competing interests}

The authors declare that they have no competing interests.

\section{Author details}

${ }^{1}$ Department of General, Trauma and Reconstructive Surgery, University Hospital Ludwig-Maximilians-University (LMU) Munich, Munich, Germany. 2 Department for Orthopedics and Traumatology, Kepler University Hospital, Johannes Kepler University Linz, Linz, Austria. ${ }^{3}$ Department of Trauma Surgery, Medical University of Innsbruck, Innsbruck, Austria. ${ }^{4}$ Depuy Synthes, Luzernstrasse 21, 4528 Zuchwil, Switzerland. ${ }^{5}$ Department for Trauma Surgery, Medical University Innsbruck, Innsbruck, Austria. ${ }^{6}$ Department for Internal Medicine and Geriatrics, Hospital Hochzirl, Zirl, Austria. ${ }^{7}$ Department of Medicine 2/Geriatrics, Paracelsus Medical University, General Hospital Nuremberg, Nuremberg, Germany.

Received: 8 April 2020 Accepted: 27 July 2020

Published online: 10 August 2020

References

1. Cooper C, Campion G, Melton L. Hip fractures in the elderly: a worldwide projection. Osteoporos Int. 1992;2(6):285-9.

2. Friedman SM, Mendelson DA. Epidemiology of fragility fractures. Clin Geriatr Med. 2014;30(2):175-81.

3. Leal J, Gray AM, Prieto-Alhambra D, Arden NK, Cooper C, Javaid MK. Impact of hip fracture on hospital care costs: a population-based study. Osteoporos Int. 2016;27(2):549-58.

4. Castelli A, Daidone S, Jacobs R, Kasteridis P, Street AD. The determinants of costs and length of stay for hip fracture patients. PLOS ONE. 2015;10(7):e0133545.

5. Haentjens P, Autier P, Barette M, Boonen S, Belgian Hip Fracture Study Group. The economic cost of hip fractures among elderly women. A one-year, prospective, observational cohort study with matched-pair analysis. Belgian Hip Fracture Study Group. J Bone Joint Surg Am. 2001;83(4):493-500

6. Hernlund E, Svedbom A, Ivergård M, Compston J, Cooper C, Stenmark J, Osteoporosis in the European Union: medical management, epidemiology and economic burden A report prepared in collaboration with the International Osteoporosis Foundation (IOF) and the European Federation of Pharmaceutical Industry Associations (EFPIA). Arch Osteoporos. 2013;8:136.

7. Vochteloo AJH, Moerman S, Tuinebreijer WE, Maier AB, de Vries MR, Bloem RM. More than half of hip fracture patients do not regain mobility in the first postoperative year. Geriatr Gerontol Int. 2013;13(2):334-41. 
8. Norton R, Butler M, Robinson E, Lee-Joe T, Campbell AJ. Declines in physical functioning attributable to hip fracture among older people: a followup study of case-control participants. Disabil Rehabil. 2000;22(8):345-51.

9. Vestergaard P, Rejnmark L, Mosekilde L. Increased mortality in patients with a hip fracture-effect of pre-morbid conditions and post-fracture complications. Osteoporos Int. 2007;18(12):1583-93.

10. Bentler SE, Liu L, Obrizan M, Cook EA, Wright KB, Geweke JF, et al. The aftermath of hip fracture: discharge placement, functional status change, and mortality. Am J Epidemiol. 2009:170(10):1290-9.

11. Prestmo A, Hagen G, Sletvold O, Helbostad JL, Thingstad P, Taraldsen $\mathrm{K}$, et al. Comprehensive geriatric care for patients with hip fractures: a prospective, randomised, controlled trial. Lancet Lond Engl. 2015;385(9978):1623-33.

12. Henderson CY, Shanahan E, Butler A, Lenehan B, O'Connor M, Lyons D, et al. Dedicated orthogeriatric service reduces hip fracture mortality. Ir J Med Sci. 2017;186(1):179-84.

13. Lau TW, Fang C, Leung F. The effectiveness of a multidisciplinary hip fracture care model in improving the clinical outcome and the average cost of manpower. Osteoporos Int. 2017;28(3):791-8.

14. Bachmann S, Finger C, Huss A, Egger M, Stuck AE, Clough-Gorr KM. Inpatient rehabilitation specifically designed for geriatric patients: systematic review and meta-analysis of randomised controlled trials. BMJ. 2010;340:C1718

15. Baztán JJ, Suárez-García FM, López-Arrieta J, Rodríguez-Mañas L, Rodríguez-Artalejo F. Effectiveness of acute geriatric units on functional decline, living at home, and case fatality among older patients admitted to hospital for acute medical disorders: meta-analysis. BMJ. 2009:338:b50.

16. Disability prevention and rehabilitation. World Health Organization Technical Report Series no 668; 1981. p. 1-39.

17. Lacasse Y, Wong E, Guyatt GH, King D, Cook DJ, Goldstein RS. Meta-analysis of respiratory rehabilitation in chronic obstructive pulmonary disease. Lancet Lond Engl. 1996;348(9035):1115-9.

18. Sandercock G, Hurtado V, Cardoso F. Changes in cardiorespiratory fitness in cardiac rehabilitation patients: a meta-analysis. Int J Cardiol. 2013;167(3):894-902.

19. Lewinter C, Doherty P, Gale CP, Crouch S, Stirk L, Lewin RJ, et al. Exercisebased cardiac rehabilitation in patients with heart failure: a meta-analysis of randomised controlled trials between 1999 and 2013. Eur J Prev Cardiol. 2015;22(12):1504-12.

20. Pollock A, Baer G, Campbell P, Choo PL, Forster A, Morris J, et al. Physical rehabilitation approaches for the recovery of function and mobility following stroke. Cochrane Database Syst Rev. 2014:4:1920.

21. Kammerlander C, Gosch M, Blauth M, Lechleitner M, Luger TJ, Roth T. The Tyrolean Geriatric Fracture Center: an orthogeriatric co-management model. Z Gerontol Geriatr. Dezember. 2011;44(6):363-7.
22. Bundesarbeitsgemeinschaft der Klinisch-Geriatrischen Einrichtungen e.V., der Deutschen Gesellschaft für Geriatrie e.V. und, der Deutschen Gesellschaft für Gerontologie und Geriatrie e.V. Abgrenzungskriterien der Geriatrie. Link: http://www.geriatrie-drg.de/public/docs/Abgrenzungskrit erien_Geriatrie_V13_16-03-04.pdf.

23. Mahoney Fl, Barthel DW. Functional evaluation: the Barthel index. Md State Med J. 1965:14:61-5.

24. Bryant DM, Sanders DW, Coles CP, Petrisor BA, Jeray KJ, Laflamme GY. Selection of outcome measures for patients with hip fracture. J Orthop Trauma. 2009;23(6):434-41.

25. Ishidou Y, Koriyama C, Kakoi H, Setoguchi T, Nagano S, Hirotsu M, et al. Predictive factors of mortality and deterioration in performance of activities of daily living after hip fracture surgery in Kagoshima, Japan. Geriatr Gerontol Int. 2017;17(3):391-401.

26. Auais M, Morin S, Nadeau L, Finch L, Mayo N. Changes in frailty-related characteristics of the hip fracture population and their implications for healthcare services: evidence from Quebec, Canada. Osteoporos Int. 2013:24(10):2713-24.

27. Aranguren-Ruiz MI, Acha-Arrieta MV, Casas-Fernández de Tejerina JM, Arteaga-Mazuelas M, Jarne-Betrán V, Arnáez-Solis R. Risk factors for mortality after surgery of osteoporotic hip fracture in patients over 65 years of age. Rev Espanola Cirugia Ortop Traumatol. 2017;61(3):185-92.

28. Kamel HK, lqbal MA, Mogallapu R, Maas D, Hoffmann RG. Time to ambulation after hip fracture surgery: relation to hospitalization outcomes. J Gerontol A Biol Sci Med Sci. 2003;58(11):1042-5.

29. Vidán M, Serra JA, Moreno C, Riquelme G, Ortiz J. Efficacy of a comprehensive geriatric intervention in older patients hospitalized for hip fracture: a randomized, controlled trial. J Am Geriatr Soc. 2005;53(9):1476-82.

30. Hulsbæk S, Larsen RF, Troelsen A. Predictors of not regaining basic mobility after hip fracture surgery. Disabil Rehabil. 2015;37(19):1739-44.

31. Penrod JD, Boockvar KS, Litke A, Magaziner J, Hannan EL, Halm EA, et al. Physical therapy and mobility 2 and 6 months after hip fracture. J Am Geriatr Soc. 2004:52(7):1114-20.

32. Wall BT, Dirks ML, van Loon LJC. Skeletal muscle atrophy during shortterm disuse: implications for age-related sarcopenia. Ageing Res Rev. 2013:12(4):898-906.

\section{Publisher's Note}

Springer Nature remains neutral with regard to jurisdictional claims in published maps and institutional affiliations.
Ready to submit your research? Choose BMC and benefit from:

- fast, convenient online submission

- thorough peer review by experienced researchers in your field

- rapid publication on acceptance

- support for research data, including large and complex data types

- gold Open Access which fosters wider collaboration and increased citations

- maximum visibility for your research: over $100 \mathrm{M}$ website views per year

At BMC, research is always in progress.

Learn more biomedcentral.com/submissions 